\title{
ACOUSTICS2008/2289 \\ Finite element simulation of the linear and nonlinear interaction of progressive acoustic waves with a standing acoustic wave field
}

\author{
E. Lamkanfi ${ }^{\mathrm{a}}$, N. F Declercq ${ }^{\mathrm{b}}$, W. Van Paepegem ${ }^{\mathrm{a}}$ and J. Degrieck ${ }^{\mathrm{a}}$ \\ ${ }^{a}$ Ghent University, Sint-Pietersnieuwstraat 41, 9000 Ghent, Belgium \\ ${ }^{\mathrm{b}}$ Georgia Tech Lorraine - G.W. Woodruff School of ME, UMI Georgia Tech - CNRS 2958, 2 rue Marconi, \\ 57070 Metz, France
}

Throughout the 20th century studies have been published on the scattering of sound by sound. It has been shown that a combination of nonlinear effects and diffraction effects exists. Approximate models have been developed and some have been verified by experiments. The report presents a finite element simulation of the effect and results in exact solutions for configuration under consideration. It is shown that, depending on the amplitude of the standing wave field, orthogonally incident sound waves diffract. A simplified model is developed for linear interactions, followed by a more realistic model incorporating nonlinear elastic effects. The study is performed in a liquid and also in a solid. Analysis is achieved by Fourier transformation and a comparison is made with diffraction laws governed by the grating equation. For simplicity a $2 \mathrm{D}$ model is presented that is extendible however to a $3 \mathrm{D}$ problem should that be necessary. Comparison with some of the earlier published approximate results is also performed. The study shows the detailed influence of the amplitude on the strength of the diffraction effect. 